\title{
WAKING EARLY AFTER HEAVY SNOW
}

While we slept, the snow

fell and pinned us to the bed, sealing

our eyes

shut, filling up

the dreaming holes of our mouths.

Waking numb, we find our bodies tangled

like wet rope, dense

as the bushes deep in the ravine,

each twig

thick as a thumb.

We wait. Slugs of light

slide through the Venetian blind, assemble slowly

on the rug, lengthen, grow fat.

At last we stagger, tug up the window lids, letting in the white eyes of day. The woods sway and start to fall apart, piece by white piece.

We fumble with spoons, bowls, eggs and struggle, like those crocuses that let their saw-teeth part too soon, and have to fight all day to hold up heavy yellow cups half-filled with snow. 